\title{
Complete pentalogy of Cantrell associated with exencephaly: a rare case report
}

\author{
Anandraj Rajasekaran ${ }^{1}$, Latha Ekanath ${ }^{2}$ \\ ${ }^{1}$ Department of Obstetrics \& Gynaecology, Mahatma Gandhi Medical College \& Research Institute, Pillayarkuppam- \\ 607402, Pondicherry, India \\ ${ }^{2}$ Department of Obstetrics \& Gynaecology, Indira Gandhi Medical College \& Research Institute, Kathirkamam- \\ 605009, Pondicherry, India
}

Received: 13 April 2014

Accepted: 4 May 2014

\section{*Correspondence:}

Dr. Anandraj Rajasekaran,

E-mail: dranandraj.mdu@gmail.com

(C) 2014 Rajasekaran A et al. This is an open-access article distributed under the terms of the Creative Commons Attribution Non-Commercial License, which permits unrestricted non-commercial use, distribution, and reproduction in any medium, provided the original work is properly cited.

\section{ABSTRACT}

Complete pentalogy of Cantrell (PC) is a rare condition with an incidence of 1 in 100000 pregnancies. The spectrum includes defects in the diaphragm, anterior abdominal wall, diaphragmatic pericardium, lower sternum and congenital cardiac anomalies. We hereby report a case of complete pentalogy of Cantrell associated with exencephaly.

Keywords: Pentalogy of Cantrell, Ectopia cordis, Exencephaly, Abdominal wall defect, PC

\section{INTRODUCTION}

Pentalogy of Cantrell was first reported by Cantrell et al. in 1958. ${ }^{1}$ The full spectrum of Cantrell's pentalogy is extremely rare and is usually lethal. The spectrum consists of five anomalies:

1. A deficiency of anterior diaphragm,

2. Midline supraumbilical abdominal wall defect,

3. A defect in diaphragmatic pericardium,

4. Congenital cardiac anomalies, and

5. Defect in lower sternum.

Complete spectrum of PC is rare; only three cases of complete PC associated with exencephaly and spinal dysraphism have been reported in literature. Our case is unique in that complete PC was associated with exencephaly alone.

\section{CASE REPORT}

A 24 year old antenatal woman was referred for multiple congenital anomalies of the foetus at 20 weeks gestation. She had one prior full term normal delivery and one spontaneous first trimester abortion.

Her ultrasound examination showed exencephaly (Figure 1), ectopia cordis (Figure 2), ventricular septal heart defect, omphalocoele (Figure 3) and oligohydramnios.

She was counselled regarding prognosis of the foetus and offered termination of pregnancy. With informed consent, oral mifepristone $200 \mathrm{mg}$ followed by one dose of $400 \mu \mathrm{g}$ vaginal misoprostol was given. She expelled fetus weighing 200 grams showing ectopia cordis, lower sternal defect, supraumbilical anterior abdominal wall defect with bowel protruding out characteristic of complete PC along with exencephaly and left club foot (Figure 4). 


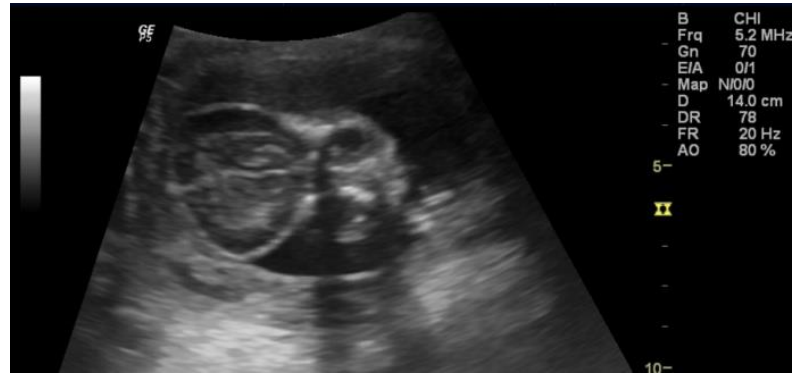

Figure 1: Coronal view of face showing exencephaly.

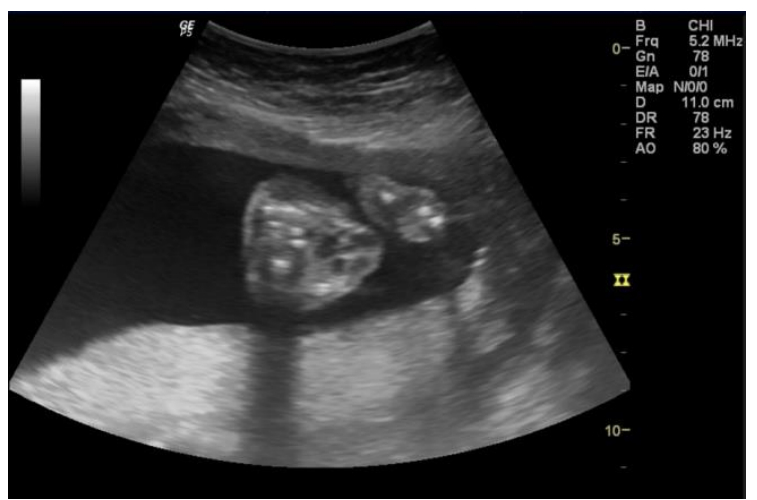

Figure 2: Transverse view of thorax showing ectopia cordis.

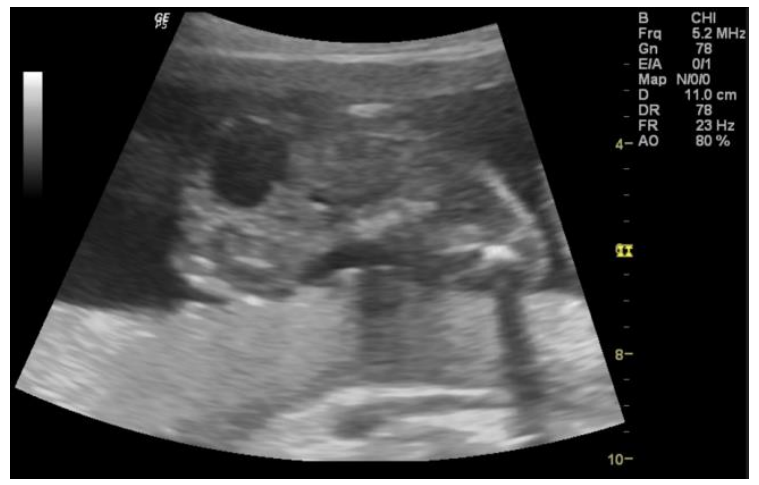

Figure 3: Sagittal view of trunk showing omphalocoele.



Figure 4: Image of expelled foetus.

\section{DISCUSSION}

Cantrell's pentalogy is a rare condition with a $2: 1$ male predominance and an incidence of less than 1 in 100000 pregnancies. ${ }^{2}$ Complete pentalogy of Cantrell, in addition to exencephaly and spinal dysraphism is even more rarely reported. ${ }^{3,4}$ In our case only exencephaly was associated with complete PC.

The exact aetiology of PC is unclear and is believed to be of sporadic occurrence. The factors proposed to be responsible are: mechanical teratogens, major gene mutation, chromosomal abnormalities such as trisomy 13 $\& 18$ and disrupted vessel defects. ${ }^{5}$

Cantrell et al proposed that this entity is due to failure of development of ventral mesoderm at about 14 to 18 days of embryonic life.

On the basis of embryonic development, this syndrome may be classified into two groups: ${ }^{6}$

1. Due to mesodermal defect which includes defects in diaphragm, pericardium and intracardiac lesions.

2. Due to failure of migration of paired structures which includes sterna and abdominal wall defects.

Toyama had proposed a classification for PC. ${ }^{2}$

Class I: exact diagnosis with five defects present

Class II: probable diagnosis with four defects (includes intracardiac and abdominal wall defects)

Class III: incomplete diagnosis with combination of defects (always accompanied by sternal defects)

Intracardiac anomalies are constantly present.

Pentalogy of Cantrell can be suspected by antenatal ultrasound. Intrauterine diagnosis before 12 weeks is not possible as herniation of bowel out of abdomen is a normal event in foetal development at that time. After 12 weeks, the differential diagnoses include omphalocoele, pentalogy of Cantrell and gastroschisis. ${ }^{7}$

If diagnosis is made by ultrasound, screening for chromosomal abnormalities is recommended. Following prenatal diagnosis, termination may be offered in severe cases especially with abnormal karyotype. ${ }^{8}$

Prognosis depends on the extent of cardiac defects, diaphragmatic and abdominal wall defects. Complete pentalogy is always fatal.

Ghidini et al. described ten cases of complete PC diagnosed antenatally by ultrasound and the outcome was uniformly fatal. ${ }^{9}$

Amniotic band syndrome with limb anomalies, structural cardiac defects with pericardial effusion, exencephaly, 
cystic hygroma, infraumbilical defects with cloacal and bladder exstrophy and bilateral inguinal hernias have been found in association with $\mathrm{PC} .^{10}$

In case of incomplete forms, a multidisciplinary approach is required to correct the thoracic, abdominal wall defects by paediatric surgeon and cardiac defects by cardiothoracic surgeon. Technical and financial constraints may be encountered precluding this line of management. ${ }^{11}$

\section{CONCLUSION}

Pentalogy of Cantrell is a syndrome with a spectrum of congenital anomalies. Obstetricians should be aware of such condition for diagnosis by antenatal ultrasound and parents should be appropriately counselled for termination of pregnancy before viability.

Funding: No funding sources

Conflict of interest: None declared

Ethical approval: Not required

\section{REFERENCES}

1. Cantrell JR, Haller JA, Ravith MM. A syndrome of congenital defects involving the abdominal wall, sternum, diaphragm, pericardium and heart. Surg Gynaecol Obstet. 1958;107:602-14.

2. Toyama WM. Combined congenital defects of the anterior abdominal wall, sternum, diaphragm, pericardium and heart: a case report and review of the syndrome. Pediatr. 1972;50:778-92.
3. Ranganath P, Pradhan M. Complete pentalogy of Cantrell with craniorachischisis: a case report. J Prenat Med. 2012;6(1):10-2.

4. Kachare MB, Patki VK, Saboo SS, Saboo SH, Ahlawat K, Saboo SS. Pentalogy of Cantrell associated with exencephaly and spinal dysraphism: antenatal ultrasonographic diagnosis: case report. Med Ultrason. 2013;15(3):237-9.

5. Chen CP. Syndromes and disorders associated with omphalocele (II): OEIS complex and pentalogy of Cantrell. Taiwan J Obstet Gynaecol. 2007;46(2):10310 .

6. Kumar B, Sharma C, Sinha DD, Sumanlata. Ectopia cordis associated with Cantrell's pentalogy. Ann Thorac Med. 2008;3(4):152-3.

7. Jafarian AH, Omidi AA, Fazel A, Sadeghian H, Joushan B. Pentalogy of Cantrell: a case report. J Res Med Sci. 2011 Jan;16(1):105-9.

8. Chandran S, Ari D. Pentalogy of Cantrell: an extremely rare congenital anomaly. J Clin Neonatol. 2013 Apr-Jun;2(2):95-7.

9. Ghidini A, Sirtori M, Romero R, Hobbins JC. Prenatal diagnosis of Pentalogy of Cantrell. J Ultrasound Med. 1988;7:567-72.

10. Sowande OA, Anyanwu LJC, Talabi AO, Babalola OR, Adejuyigbe O. Pentalogy of Cantrell: a report of three cases. J Surg Tech Case Rep. 2010 JanJun;2(1):20-3.

11. Khanna PC, Bharati A, Merchant SA. Pentalogy of Cantrell or one of its variants. Appl Radiol. 2005;34(10):40-3.

DOI: $10.5455 / 2320-1770$. ijrcog20140645

Cite this article as: Rajasekaran A, Ekanath L.

Complete pentalogy of Cantrell associated with exencephaly: a rare case report. Int J Reprod Contracept Obstet Gynecol 2014;3:483-5. 